\title{
10. Beyond Promotion: The UN Global Goal Campaign
}

\author{
Bo Florin
}

\begin{abstract}
'Beyond Promotion: The un Global Goals Campaign', deals with the latter as a particularly interesting example, given the way this campaign did not advertise a product, but rather a policy. Does this change the way of relating to history? Advertising sustainability requires both economic development, environmental protection, and social responsibility. The chapter shows that the launch of this campaign, not least by using Aardman Animations, relies heavily on both film history and the history of commercials.
\end{abstract}

Keywords: United Nations, Global Goals Campaign, policy, film history

As the United Nations in 2000 adopted the eight Millennium Development Goals for Sustainable Development, which in 2015 were replaced with the seventeen Sustainable Development Goals, the focus of world politics and policies gradually shifted towards creating a sustainable future for the planet and for human societies. Looking back at the two previously discussed brands, Volvo and H\&M, it becomes clear that this major shift also marks a change in advertising strategies, as values concerning sustainability are gradually entering into, challenging, and changing the companies' advertising agendas.

When you talk about Volvo, you probably think of a car. But you are wrong. What Volvo is about today is rather an assemblage, an exhaust emission control device put together with a number of other devices, all designed for sustainability.

Florin, B., P. Vonderau, Y. Zimmermann, Advertising and the Transformation of Screen Cultures. Amsterdam: Amsterdam University Press, 2021 DOI 10.5117/9789462989153_CH1O 
The quote, attributed to a Volvo salesperson, points to the fact that sustainability has really become a core value in advertising today, marketing the quality of sustainable solutions rather than the product itself. ${ }^{1}$

On the Volvo home page in 2016, the year after the adoption of the Global Goals, there is a double focus on sustainability - 'we've reduced their impact on the environment' - and on the future, on 'entering a new era.' ${ }^{2}$ Already with the new millennium - coinciding with the UN adoption of the Millennium Development Goals - Volvo had delivered its first sustainability report. The yearly reports from 2004 onwards are available on the home page, after the practice first became formalized in 2003. The same year, a new commercial for Volvo S 60 was also launched: 'Jogger', produced by Forsman \& Bodenfors. ${ }^{3} \mathrm{~A}$ woman is sitting behind the wheel in an urban environment. She is distracted by the sight of a jogger in her rear-view mirror; he is running just behind her car. More joggers join. Although she switches lanes, the joggers - now a small crowd - continue to run behind her car, ignoring the rest of the traffic. A slogan explains: 'A car that turns harmful ozone into oxygen.' The ad was reported to the Swedish Marknadsetiska rådet (The Council on Market Ethics), which found that it broke the rules of the International Chamber of Commerce (ICC). The slogan was later prohibited by a decision in the Swedish Market Court. ${ }^{4}$ This, however, hasn't changed Volvo's basic strategy, to claim a unique consciousness of environmental and sustainability issues, based on the argument that '[w]e come from a different place. So we think about cars in a different way. It's in our nature'. 5

1 Quoted from Jack Spaapen at a seminar on quality assessment with the Swedish Research Council at Stockholm Waterfront, 15 June 2016.

2 Volvo website (Sweden), https://www.volvocars.com/sg/cars/new-models/vgo-old/madeby-sweden (last accessed 6 April 2021); Volvo website (UK), http://www.volvocars.com/uk/cars/ new-models/ninety (last accessed 6 April 2021). It is interesting to note that versions vary. The Swedish as well as the global version are more elaborated than certain national versions, such as that of the United Kingdom. The former states that: 'because this is what the world needs', or 'because this is what the future requires'.

3 'Volvo - “Jogger"', Adforum.com, http://www.adforum.com/creative-work/ad/player/23867/ jogger/volvo (last accessed 6 April 2021).

4 Sveriges Domstol, Marknadsdomstolen, Domstolsnummer 2004-4, Avgörandedatum 200402-10, Referat MD 2004:4, http://www.rattsinfosok.dom.se/lagrummet/index.jsp (last accessed 15 July 2017).

5 Volvo website, https://www.volvocars.com/sg/cars/new-models/v9o-old/made-by-sweden (last accessed 6 April 2021). Recently, Volvo also announced their support of the UN Global Compact: 'As a founding member of the Un Global Compact, Volvo Cars is delighted to have hosted the Nordic Network of the world's largest corporate sustainability initiative on 8-9 May 2017. The Compact is the world's largest and most influential corporate sustainability initiative with 
Like Volvo, H\&M has also been subject to criticism for breaking international conventions, though in their case, this criticism had no relationship to advertising, which was rather used as a remedy, a means of re-establishing the company's reputation. After a number of reports on suspected child labour, ${ }^{6}$ in 2013 H\&M established a playlist on their YouTube channel called 'H\&M Conscious', which today contains 25 films. ${ }^{7}$ The content ranges from short ads - 'H\&M All for Children 2013' (in support of UNICEF) or 'H\&M in Bangladesh' - to seminars for H\&M staff filmed in their entirety. That social responsibility and sustainability has become a key question for the company is obvious to anyone consulting the playlist. In a seminar from 2016, it is stated that 'Turning from linear "take, make, waste" to circular productions where products and resources are used again and again is a key challenge for the fashion industry'. This is also the subject of two recent commercials on recycling, which have both generated a huge public response. In 2015, a film with the 'Godfather of Punk', Iggy Pop, called 'Close the Loop', was produced by Forsman \& Bodenfors under the label 'Sustainable fashion through recycled clothes', with almost ten million views. ${ }^{8}$ Through a series of dichotomies 'Stand out - blend in', 'Be trashy - be neat', or 'rule-breaking' advice - such as to 'wear red as a redhead' or 'wear yellow as a blonde' - the final slogan sets the basic rule: 'There are no rules in fashion but one: recycle your clothes!' Under the same label, a music video was produced in 2016, also by Forsman \& Bodenfors, 'World Recycle Week featuring M.I.A.', with three million views, with the final slogan, 'Join in a global fashion movement for the planet'. ${ }^{9}$ Through the slogan 'Reworn - reused - recycled', H\&M has strived to establish its image as a fashion brand that has made circularity, and thus sustainability, its guiding star. How, then, do these two particular cases relate to a broader context of advertising in the age of sustainable development?

over 9,0oo companies in 170 countries.' http://www.volvocars.com/intl/about/our-company/ sustainability (last accessed 6 April 2021).

6 See Jamie Doward, 'H\&m Comes under Pressure to Act on Child-Labour Cotton', The Guardian, 15 December 2012, https://www.theguardian.com/business/2012/dec/15/cotton-child-labouruzbekistan-fashion (last accessed 6 April 2021).

7 H\&M's official YouTube channel, https://www.youtube.com/hm (last accessed 6 April 2021).

8 'Close the loop', https://www.youtube.com/watch? $=\mathrm{v}=\mathrm{s} 4 \mathrm{xnyr} 2 \mathrm{mCuI}$ (last accessed 6 April 2021).

9 'World Recycle Week featuring M.I.A.', https://www.youtube.com/watch?v=f7MskKkn2Jg (last accessed 6 April 2021). The ad 'Bring it on' (2017), also by Forsman \& Bodenfors for H\&M, goes even further, and shows more explicitly the idea of recycling: http://www.fb.se/work/hm/ bring-it-on (last accessed 6 April 2021). 


\section{From Basic Marketing to the Sustainability Goals}

In their book Sustainability Marketing: A Global Perspective, Frank-Martin Belz and Ken Peattie describe a development based in the eoth century, 'the century that transformed the world'. The threshold of the new millennium was an occasion to reflect on 'the state of the world and the future prospects for humankind', and thus also - within marketing business - on the marketing of the future. ${ }^{10}$ In their study, they show how the four P's put forward by E.J. McCarthy in Basic Marketing 1960 - product, price, promotion, place - were replaced by four C's, as suggested by Robert F. Lauterborn in a 1990 article in Advertising Age: consumer wants and needs, cost, communication, and convenience. ${ }^{11}$ This also marks a shift of focus from producer to consumer, paving the way for 'a new sustainability-oriented marketing mainstream, ${ }^{12}$ which is the vision of the authors, oriented towards the future and built on sustainable consumer solutions and relationships. In 2012, in a late edition of his book Marketing Management, Philip Kotler takes this one step further, by arguing for four new P's: people, processes, programmes, and performance..$^{13}$ In the 21 st century, the focus has passed well beyond the producer-consumer dichotomy.

It could be argued that Kotler's non-dualistic approach focusses on more all-embracing, 'softer' values, or even that it is more value-oriented in general. However, while any ad for a commodity necessarily also contains values, which may change over time with the change of values in society - as the examples of Volvo or H\&M clearly show - another type of change occurs when what is being advertised is no longer a commodity at all, but instead a set of values. The very idea of marketing still remains closely related to the launch of products and services for a market, with the aim to create a behavioural change in the consumer and thus to generate profit. These products and services are mostly launched through images, or rather, they have become images themselves. Does the marketing of 'pure values', then, differ from that of commodities, in principle or in practice? These questions have become all the more relevant as sustainability itself has become the object of marketing. The United Nations has communicated the seventeen

10 Frank-Martin Belz and Ken Peattie, Sustainability Marketing: A Global Perspective, 2nd ed. (West Sussex: Wiley 2012), $6 \mathrm{ff}$.

11 See E.J. McCarthy, Basic Marketing: A Managerial Approach (Homewood: Irwin, 196o); and R.F. Lauterborn, 'New Marketing Litany: 4 Ps passé; C-Words Take Over', Advertising Age (1 October 1990), 26.

12 Belz and Peattie, Sustainability Marketing, xiv

13 Philip Kotler, Marketing Management, 14th ed. (Harlow: Pearson, 2012 [1967]), 25. 
Sustainable Development Goals, agreed upon by the General Assembly in 2015 , to the world, not only through traditional political or news channels but also through advertising films, circulated both through traditional and social media, in 'any and many ways'. ${ }^{14}$ In the following, I will explore a part of these 'ways', with a specific focus on the Global Goals Campaign, launched in 2015 within the United Nations Development Program (UNDP).

The aim of this campaign - which corresponds well with Kotler's four P's - people, processes, programmes, and performance - is broad. What is at stake is the survival of the planet and, in the end, even of the human species. Not only the United Nations itself, but all their member states, are committed to realizing the goals, which are implemented in different ways in each country. The Global Goals Campaign has been described as 'the biggest ever collaboration of NGOs, global brands, public figures, educators, sports clubs, faith leaders, TV and Radio broadcasters, Cinema Advertising companies, telecoms operators, digital and social media platforms, creative and media agencies, publishers, artists and grassroots organisations.' ${ }^{15}$

What is particularly interesting with this campaign is that it was created by the United Nations with a global and non-profit aim. A possible parallel that comes to mind would be the PSA - public service announcements - a format for sponsored productions delivering messages in the public interest, with the aim to change attitudes and behaviours towards social issues, and which thus also clearly articulate certain values and priorities. The comparison is perfectly valid, especially when it comes to the individual parts of the campaign, but still, it can be argued that the Un campaign aims at an even larger format than creating a number of PSAs only. The ambition is to advertise the goals through a very broad range of forms and formats - including a specific campaign within the campaign, inviting companies to join a 'Make a PSA'. ${ }^{16}$

A key moment of the initial launch of the Global Goals Campaign was the initiation of 'Project Everyone' by screenwriter and film director Richard Curtis, with the aim to advertise the Sustainable Development Goals: 'The

14 Richard Curtis in 'Making the SDG's famous,' https://www.youtube.com/watch?v=rKir2GhwXCw (last accessed 6 April 2021).

15 SAWA/The Global Goals press release, 11 September 2015, 2,

https://press.ncm.com/press-releases/press-release-details/2015/The-Cinema-Medium-Preparesfor-the-Release-of-the-First-Ever-Global-Cinema-Ad-Campaign-to-Promote-the-Launch-of-theUnited-Nations-Global-Goals/default.aspx (last accessed 6 April 2021).

16 United Nations, Creative Community Outreach Initiative (CCOI) https://www.un.org/en/ ccoi/page/make-psa (last accessed 6 April 2021). 
simple but mighty ambition of Project Everyone - is to share the global goals with all 7 billion people on this planet'. ${ }^{17}$ Though independently organized, Project Everyone has indeed been part and parcel of the launch of the Global Goals by the UNDP. A YouTube clip featuring Helen Clark, Head of the UNDP, particularly emphasizes the partnership between UNDP and Project Everyone..$^{18}$ The Project Everyone home page equally emphasizes the close connection to the United States by quoting UN Secretary Special Adviser Amina J. Mohammed, who states that '[w]e welcome the extraordinary contribution and commitment from Richard Curtis and the Project Everyone team to make these global goals famous.' ${ }^{19}$ The idea was born out of a conviction that the failure of the Millennium Development Goals was partly due to the fact that they hadn't been spread widely enough and had simply remained unknown to the general public. Project Everyone is being realized in many different ways and through all channels available including, in Curtis's own words, 'online, digital, schools, faith, Tv, radio'. The examples of dissemination strategies are quite varied: the 'World's Largest Lesson' reached 500 million children in 103 countries through commitments from Ministries of Education; mobile operators texted 5.2 billion customers; the Global Citizen Festival attracted 6o,ooo live spectators and was broadcast on TV in 26 countries, with the ambition of becoming a yearly event until 2030; 1.3 million people shared \#globalgoals on social media; 250 million people engaged via Radio Everyone in 75 countries through 600 radio partners. ${ }^{20}$

A number of films have also been created and uploaded to the Global Goals home page, such as the film 'No Point Going Halfway' from 3 September 2015. ${ }^{21}$ This film links back to the Millennium Development Goals, with the general aim to highlight that many results have actually been achieved over the preceding fifteen years: 43 million more kids go to school, new HIV infections have been reduced by 40 per cent, two billion people have access to cleaner drinking water, and extreme poverty has been halved. These are facts that, according to the Global Goals Campaign, need to be told and retold, and they offer a factual framework that allows the audience to better prepare for the new ads to come and for a more positive reading of the new

17 Project Everyone, home page, https://www.project-everyone.org (last accessed 6 April 2021).

18 'Helen Clark on the launch of the Sustainable Development Goals', https://www.youtube. com/watch?v=vSFIxHQmk_4\&index=28\&list=PLhanS7jySFTJDozpollZiRREPilDkJvE4 (last accessed 6 April 2021).

19 Project Everyone, home page, https://www.project-everyone.org (last accessed 6 April 2021).

20 Ibid.

21 'No Point Going Halfway', https:/www.youtube.com/watch?v=DdLqiTvFwJk (last accessed 6 April 2021). 
goals; they are not picked out of the blue, but are only a consequent way to follow up on what has already been achieved. It is also a way to, afterwards, advertise the Millennium Development Goals. Here, however, I will focus on the two major film projects launched by Project Everyone in connection to the decision about the goals on 25 September 2015.

\section{We the People}

On 3 September 2015, there was a first launch of the four-minute-long 'We the People', featuring a performance group of teenagers, Get Lit, from high schools in Los Angeles County. ${ }^{22}$ Here, spectators were encouraged to 'join the world's biggest cast and film yourself saying your favourite goal', all to 'ignite the world's leaders'. The spectators addressed in this launch were further encouraged by the more concrete fact that, in the final film, they might star alongside actors such as Meryl Streep, Cate Blanchett, or Daniel Craig; scientists such as Stephen Hawking; musicians such as Chris Martin or Stevie Wonder (also Un Messenger of Peace); royalty such as Queen Rania of Jordan; artists such as Ai Weiwei; or other prominent people such as Bill and Melinda Gates or Nobel Peace Prize winner Malala Yousafzai - all this taking place 'on Tv, online and live'. For each goal, the phrase 'We live in a world where...' is repeated (e.g., 'where nobody, anywhere, will live in extreme poverty'), each sentence anticipating the fulfilment of one of the goals.

On 24 September, the final three-minute film was launched, which, apart from repeating the phrases from the first ad, also adds both the 'stars' and a large number of 'ordinary' people alongside the Get Lit group, to express the fact that these goals concern us all as global citizens. ${ }^{23}$

Following the same dramaturgical pattern as the 'call for contributions', the result nevertheless becomes much more complex both visually and aurally. That the film is crowd-sourced is one of its most striking features, as is the fact that that the general public and high-profile public figures appear together, and together turn to the spectator in direct address - a strongly rhetorical address. The direct address on-screen for rhetorical purposes is also strongly linked to the media history of the United Nations, which, as Pelle Snickars among others has noted, was to an important extent

22 'We the People needs you feat. Get Lit', http://www.un.org/sustainabledevelopment/ blog/2015/og/we-the-people-needs-you-global-goals (last accessed 6 April 2021).

23 “We The People" for The Global Goals': https://www.youtube.com/watch?v=RpqVmvMCmpo (last accessed 6 April 2021). 


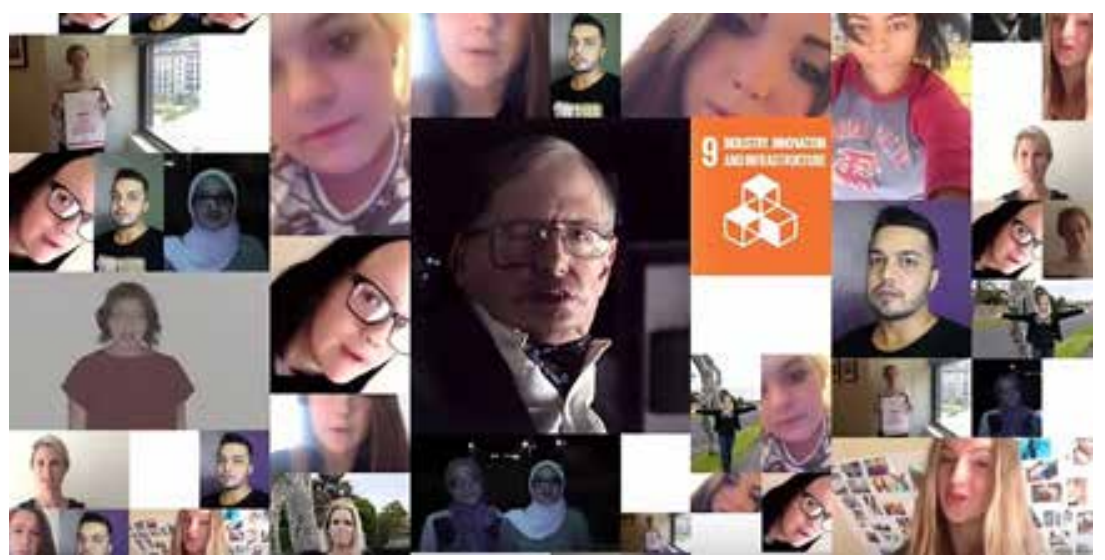

Figure 10.1: Fame and ordinariness - Stephen Hawking in 'We the People'.

developed by Secretary General Dag Hammarskjöld, who early on adopted a strategy for the 'mediatisation of politics', using the power of media to influence opinion as part of his diplomatic mission. A central part of this was his speeches on UN Day and on other important occasions in direct address to the spectator and often also in different languages (English, German, French, Swedish), which were filmed to reach out to and address spectators around the globe. ${ }^{24}$

'We The People' delivers testimonials from both celebrities and ordinary people. While clearly endorsing celebrity, the celebrities are mixed with other contributors to the film in a way that does not allow for any real distinction between fame and ordinariness. ${ }^{25}$ This, indeed, is a key message: these addresses concern us all. People also appear as representatives of whole sectors of society. Some are filmed in their home environment, thus representing anybody or everybody. Some, such as Chris Martin, who is filmed in his music studio, or football player Kolo Touré, who is filmed with the Liverpool emblem behind him, become representatives for sectors of society; Liverpool is also one of the football teams supporting the so-called Dizzy Goal Challenge, 'A Dizzy Penalty for the Global Goals. ${ }^{26}$ The

24 Pelle Snickars, 'Hammarskjöld tog kommandot över medierna', SvD (28 July 2005). See also Bo Florin and Astrid Söderbergh Widding, 'Dag Hammarskjöld i FN:s filmarkiv', Signum 1 (2006): 12-17. For Hammarskjöld's speech, see: https://www.youtube.com/watch?v=HuppZpNG $3 k Q$ (last accessed 6 April 2021).

25 For a short history on, and definitions of, testimonials and endorsements, see Patrick Vonderau's chapter 'Advertising as Commercial Speech' in this book.

26 The idea is to film as you take a spin and then try to shoot a goal, and if you miss, to add: 'I missed my goal so that world leaders don't miss theirs'; or if you score: 'If I can score a dizzy 
participants in 'We the People' obviously share the same goals - but they also share sentences: one person starts, another continues the same sentence, and a third person may finish it. During several key moments throughout the film, the many different voices also join into a chorus, whether it is in the introduction or in reading out parts of the goals together. They also share screen space: whereas some people - mostly high-profile figures - appear alone on-screen, these single shots are interwoven with split-screen shots, in which many people are represented, and global diversity is emphasized. Two pictures stand out: the portrait of Stephen Hawking, the only one with a cut from full shot to close-up, as if to particularly emphasize his authority, and the image of a person demonstrating sun panels on an outdoor roof corresponding to the seventh goal of affordable and clean energy - one of the few times that the film abandons its individual focus and indoor space format, and also the only time that it comes close to suggesting a way to actually realize the goal.

The seventeenth and last goal, 'Partnerships of all kinds', is followed by a unanimous declaration: 'Let's go to work! Let's make it happen!' The whole dramaturgy of the film is based on a productive and creative tension between unity and diversity - we, the people, are one, but we are also many. In the end, after the seventeenth goal, the voices are once again dissolved into disparity. But at the same time, as the image zooms out, many frames appear on-screen, rapidly proliferating, and we see people's faces, all in agreement, which finally transform into a globe, where miniature pictures of people come to form images of the different continents - a picture that then in turn is transformed into the logotype for the Sustainable Development Goals. This final sequence reinvents the end of Richard Curtis's earlier film Love Actually (2003), in which, towards the end, an increasing number of small frames form a heart. This ending corresponds well with the fact that the film has a highly emotional tone in addressing the spectator, with the ambition of creating 'a shareable manifesto for change by the people, of the people, for the people', ${ }^{27}$ which also adds to the strong rhetorical message that these questions are fateful indeed, of utmost importance for the survival of our planet and of the human species. The fact that 'We the People' are also the first three words in the preamble to the American Constitution lends a dignity to the campaign as such while also emphasizing its importance 
as a message deriving its power from popular sovereignty. ${ }^{28}$ In a way, it could be said to widen the American address to its citizens to embrace all people around the globe.

\section{We Have a Plan}

Another part of the 'Project Everyone' on-screen was realized simultaneously, 'The First Ever Global Cinema Ad', titled ‘\#WEHAVEAPLAN’. It was directed by advertising executive Sir John Hegarty, from Bartle Bogle Hegarty (BBH), in collaboration with Darren Dubicki at Aardman Animations and Global Cinema Advertising Association (SAWA), with Liam Neeson and Michelle Rodriguez lending their voices to the film and with music by Peter Gabriel. In this film, the idea was to reach cinema audiences all over the globe during the week immediately following the release of the goals. A leaflet from sAwA states in the headline: 'The cinema medium prepares for the release of the first ever global cinema ad campaign to promote the launch of the United Nations Global Goals'. ${ }^{29}$ After mentioning the partners in the United States - Cinema Advertising Council (CAC), a national non-profit trade association, Members National CineMedia (NCM), Screenvision, and Spotlight Cinema Networks - the aim of the campaign is expressed:

The Global Goals campaign has just been announced with a bid to reach 7 billion people in 7 days with news of the Global Goals for Sustainable Development. This unprecedented effort will culminate on 25 September at the UN when 193 world leaders adopt the Global Goals, a series of 17 ambitious targets to end poverty, fight inequality \& injustice and tackle climate change for everyone by 2030. If the goals are famous - if people care about what has been promised by the politicians, it greatly increases their chance of being implemented. So today the campaign is calling on everyone to help make the goals famous. ${ }^{30}$

The ad was first launched through a teaser campaign with a 20-second film, ${ }^{31}$ screened in 30 different countries in fourteen languages, with a

\footnotetext{
28 'Constitution USA with Peter Sagal', http://www.pbs.org/tpt/constitution-usa-peter-sagal/ we-the-people/\#.V4tBrHhYFUN (last accessed 6 April 2021).

29 SAwA/The Global Goals press release, 1.

30 Ibid.

31 SAwA Global Cinema Teaser for the United Nations Global Goals, https://www.youtube. com/watch?v=wF-9Pqnw9PQ (last accessed 6 April 2021).
} 
voice-over from the late Nelson Mandela, from his famous speech 'Make Poverty History', which he delivered at Trafalgar Square in $2005 .^{32}$ The first shot, seemingly a satellite hovering above the globe, also contains the Un logotype, and the slogan: '193 leaders meeting to agree on a plan.' The UN logo is then changed for Global Goals logotype, and the slogan: 'Reaching 7 billion people in 7 days.' Nelson Mandela's message picked for the ad is short but deep: 'Poverty is not natural. It is man-made. And it can be overcome.' As he starts speaking, to the slogan 'No Poverty', there is a cut to an image of black hands under fresh running water. The next cut, to a class where small children, both girls and boys, all raise their hands, is followed by the slogan 'Reduce Inequalities'. A third image, with the slogan 'Protect the Planet', shows an iceberg floating in the sea. As Mandela stops talking, there is a cut back to the initial picture of the globe, with the slogan '\#WEHAVEAPLAN, The First Ever Global Cinema Ad Campaign', 'Coming September 2015'. The teaser thereby succeeds both in delivering a key message, which might be extended from poverty to all of the other Sustainable Development Goals, of specifically pointing to the three main groups of goals - poverty, inequality, climate - and to promote not only the unique decision of the United Nations but also the uniqueness of the campaign as such. The choice of Nelson Mandela's voice from this key moment also links the Sustainable Development Goals to similar efforts in the recent past, in line with the earlier Millennium Development Goals, and so makes them a link in a larger chain of events aimed at making the world a better place. Mandela's voice also joins together the dead and the living, thus embracing past, present, and future.

The full ad lasts for 60 seconds. ${ }^{33}$ It premiered at the AMC Empire 25 in New York City on the eve of the Global Goals launch, 24 September, and on 25 September it was screened on thousands of cinema screens all around the world, distributed globally by UNIQUE DIGITAL. From 25 September to 2 October, it was screened at over 4000 cinemas in countries from Japan to South Africa, from Finland to Oman. The idea was to continue the screenings until the end of the year, wherever possible. The ad also launched the Global Goals Interactive App, produced by CINIME International, in order to ‘\#telleveryone'. In a behind-the-scenes video, the director Sir John Hegarty

32 'Nelson Mandela Speech in Trafalgar Square', https://www.youtube.com/watch?v=1NennMCLG7A (last accessed 6 April 2021).

33 'First Ever Global Cinema Ad \#WEHAVEAPLAN \#GlobalGoals - FULL ADVERT', https:// www.youtube.com/watch?v=7V3eSHgMEFM (last accessed 6 April 2021). 
states that 'the cinema now speaks directly to the audience'; unlike any other screening, the audience is here asked to leave their mobiles on, 'and the actual ad on screen will communicate with your phone'. The idea was to 'connect the power of the big Screen to the magic of the small screen and share the Global Goals. ${ }^{34}$

The ad first shows the globe at a distance, as in the teaser, but with an explanatory message, repeating the title of the ad: 'We have a plan to end poverty, reduce inequalities and fight climate change.' The next image shows an 'animated' un building from above, from a 'God's-eye view' perspective. This is followed by an image from below, of a number of flags outside the building, accompanied by the text Un Headquarters, to the sound of sirens and with rapidly passing vehicles. Then, after a cut to a garage, vehicles are seen arriving, escorted by police motorbikes. The surveillance camera (highlighted by a close-up shot) adds to the seriousness of the issue, and a number of screens imply that this is something being telecast in real time through several channels across the globe. A cut and a zoom in towards the rostrum in the UN General Assembly Hall surprisingly reveals a llama entering the stage, obviously personifying the Head of UNDP Helen Clark from New Zealand. While the physical environment is familiar, all of the other delegates also turn out to be animals, each personifying its particular country. The llama now announces that 'We have a plan', and that 'the plan is agreed by everyone!' It is interesting to note that the teaser doesn't reveal anything about the film being an animation, in order to increase the surprise effect.

But why animals? According to Andreas Fuchs, the director Sir John Hegarty, who wanted to celebrate the historical moment of the adoption of the Global Goals with his film, still asked himself how to put some drama into this. He then came up with the idea 'to use every country's national animal instead of the delegates, and show that they could come together? And if they can come together, then this shows that we can all do it.....35

Despite apparent minor disagreements between delegates, all of the animals basically seem to share the vision of the llama. The prophetic resonances of a messianic moment when hostile animals are reconciled

34 'World's first cinema ad from SAWA', The Global Goals website, http://www.globalgoals. org/cinema/ (last accessed 6 April 2021).

35 Andreas Fuchs, 'Noble Goals: Marketing the First-Ever Global Cinema Ad Campaign', Film Journal International, 28 September 2015, http://fijj.webedia.us/features/noble-goalsmarketing-fijirst-ever-global-cinema-ad-campaign (last accessed 6 April 2021). 


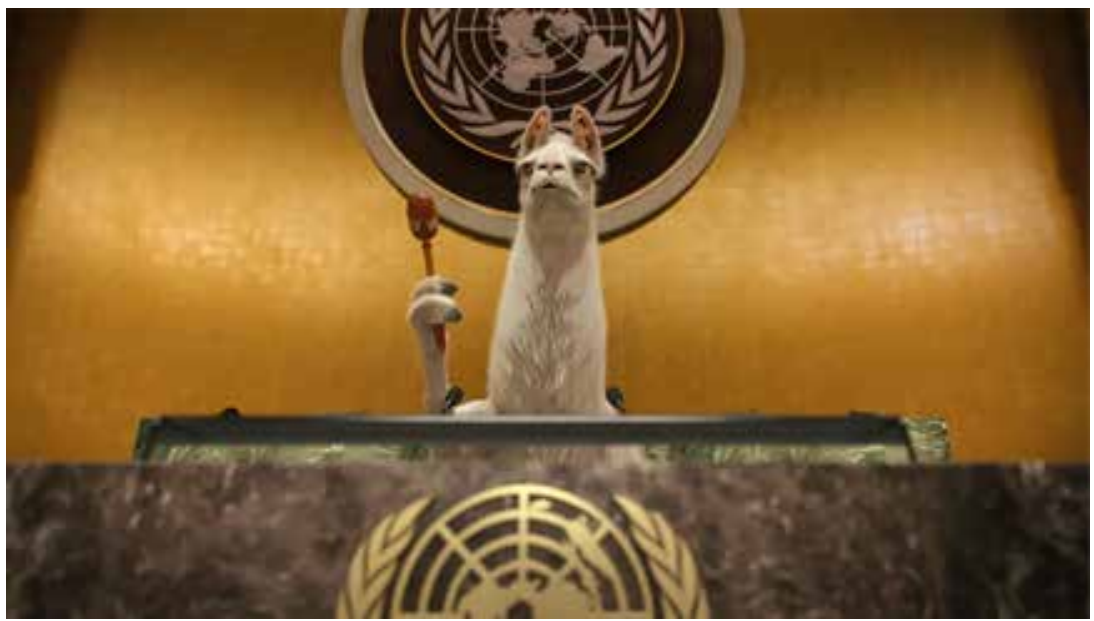

Figure 10.2: UN General Assembly Hall (and Head of undp Helen Clark?) in 'We Have a Plan'.

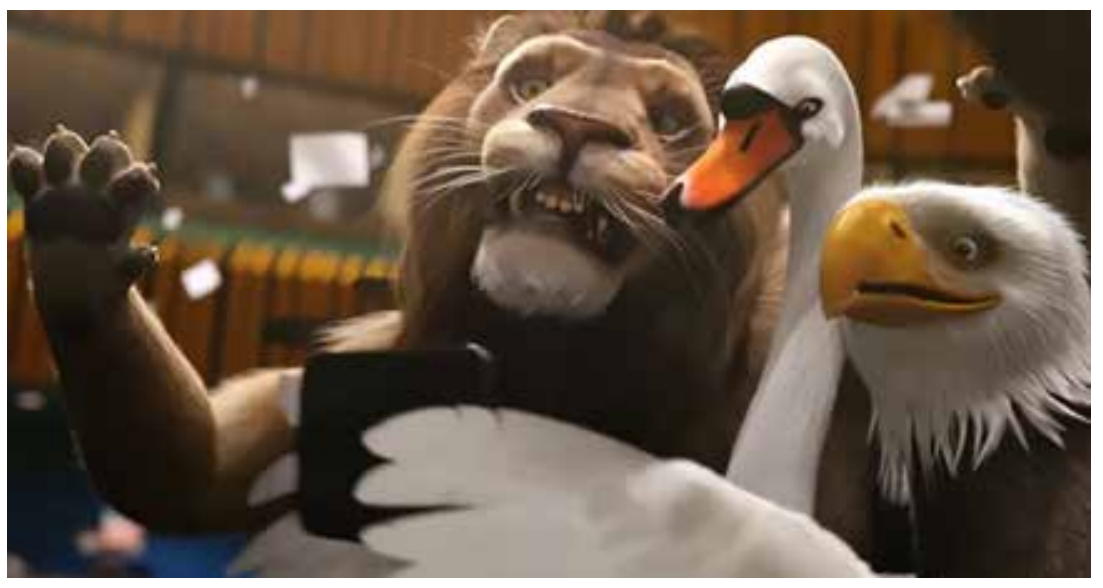

Figure 10.3: Biblical references in 'We Have a Plan'.

should be obvious for viewers with a biblical cultural heritage; the moment of adopting the Global Goals by the UN is indeed kairos, the right moment for the planet. ${ }^{36}$

The use of animals, however, must also be considered in relation to the historical role of Aardman animations within British advertising film. Here, the Creature Comforts advertisements, produced from 1990 to 1992, marked an important shift in British television advertising, analysed among others 
by Renée Dickason. She saw Creature Comforts as a clear case in point, introducing 'the caring nineties', as she calls them:

There was certainly plenty of evidence in the advertisements of the time, to suggest that the egoism of the 1980 s had disappeared, even if the term 'caring' is open to a variety of interpretations. One meaning of the expression was the desire to make life comfortable and easy for oneself. ${ }^{37}$

But if Creature Comforts did leave a mark in British advertising history, it was less as an ad for electricity - indeed, as Malcolm Cook has shown, the trade press at the time wrongly attributed the ads to a gas company - than as a trademark in itself..$^{8}$ Cook writes:

Regardless of the effectiveness of these commercials for the client brand, Heat Electric, in shifting to the use of characters created for other purposes, the 'Creature Comfort' commercials start to assert the Aardman studio's distinctive authorial voice and style as the dominant feature of its work at the expense of the brand being promoted. It may even be argued the brand the 'Creature Comforts' commercials most effectively promoted was Aardman itself. 39

The use of animals thus not only makes reference to a strong brand, where the use of animals already in the early 1990s had marked the shift from consumerism to sharing and caring, but in fact continues in the same vein, now using the Aardman brand and its popularity among the general public to promote the global goals.

Apart from their common overall message, the two films also share an interesting media-specific dimension. In an interview, sAWA General Manager Cheryl Wannell commented on the project: 'The aim is to make these goals FAMOUS, and what better place to do that than on the big screen? Cinema educates, inspires and influences people by changing hearts and minds'.$^{40}$ In a similar vein, President of Sales and Marketing with National CineMedia Cliff Marks stated, in a hyperbolic claim:

37 Renée Dickason, British Television Advertising: Cultural Identity and Communication (Luton: University of Luton Press 2000), 92.

38 Malcolm Cook, “All You Do Is Call Me, I'll Be Anything You Need”: Aardman Animations, Music Videos and Commercials', in Beyond Stop-Motion Film: Production, Style and Representation in Aardman Animations, ed. Annabelle Honess Roe (London: Bloomsbury, 2020).

39 Ibid.

40 SAWA/The Global Goals press release, 1. 


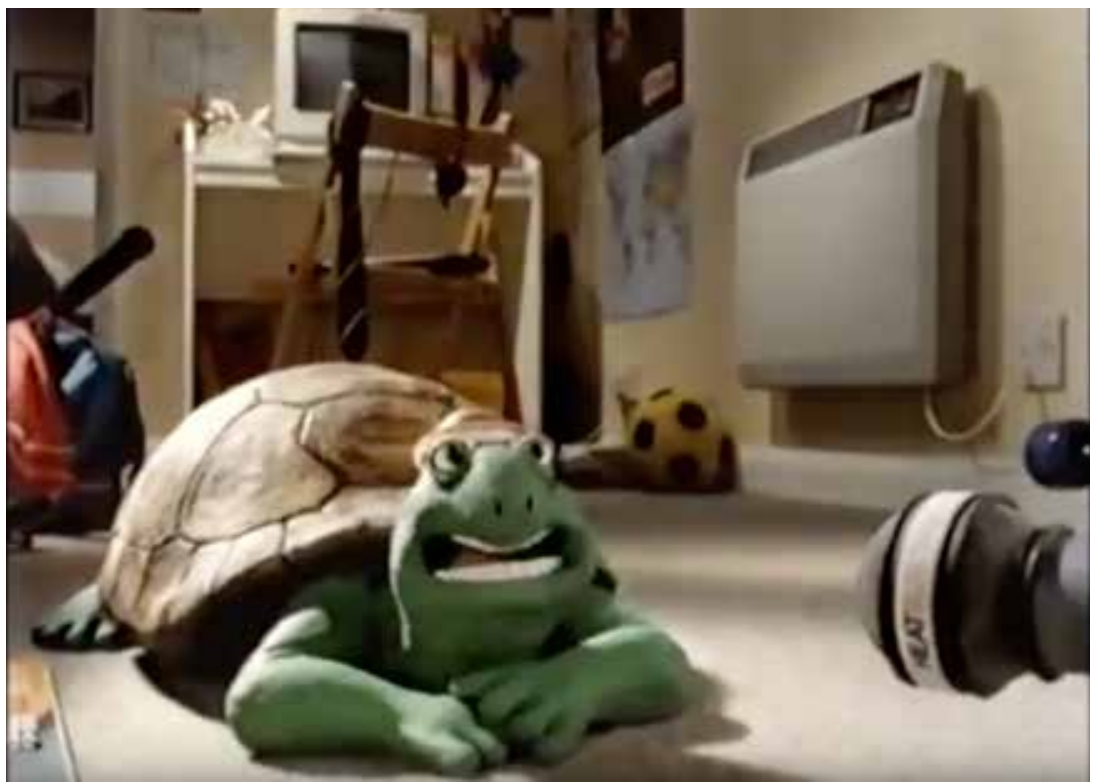

Figure 10.4: Screen ad for Heat Electric by Aardman animations Ltd., 1990.

Cinema has so many powerful storytelling capabilities, and to think that the UN chose our medium to most profoundly share their Global Goals [...] in movie theatres around the world speaks volumes about the engagement and emotional connection of our 50 -foot screens. Today's millennial audiences truly want to help change the world, and the best place to reach them with this important message is at the movies. ${ }^{41}$

As already noted, the connection between the cinema ad and the mobile app was here used to create a unique combination. From a media historical perspective, however, it is particularly interesting to note the emphasis on the big screen from both of these media representatives. The hyperbolic claims from Wannell and Marks about the great potential of cinema even today, based on the historical weight that it carries, is unanimous: the large screens, the storytelling capacity of the movies, as well as their potential to engage and to change minds. For an audience used to manifold media, many screens, and small screens, the impact of the big, 50-foot screen here takes on an almost solemn quality: only the cinema medium seems to be really apt or suitable to convey the importance of this message. Though launched as 'big screen' ads, it is however clear 
that in practice, they have also allowed for widespread resonances across other media channels.

Another take on the relation between cinema and the project of advertising the goals was offered by a second 'We Have a Plan' ad, this time released on YouTube on 16 September 2016 by the UNDP. On the one hand, cinema was not introduced here through the format of the big screen. On the other hand, it was just as present, since the film is almost entirely (1:23 minutes) made up of a series of quotations from famous films, organized in three steps. After the initial 'We have a problem', from Ron Howard's Apollo 13 (1995), a number of quotes, starting with Gone Girl (David Fincher, 2014), ask the rhetorical question: 'What's the plan?' In the next step, a number of new quotes, introduced by the lemur from Madagascar (Eric Darnell \& Tom McGrath, 2005), proclaims that 'I have a plan', and finally, a number of statements praise the plan. ${ }^{42}$

The choice of the film format by the United Nations, albeit in different ways, plays an important role here: among all media, cinema was selected to transmit this unique event in history. The advertisers thus show confidence in the cinema as a privileged arena for transmitting a key message. The idea of cinema as the moving image medium par excellence may appeal to older audiences with a film-historical background, as well as to cinephiles of all ages. But the fact that audiences are told to leave their mobiles on suggests that the ad is addressed mostly towards younger audiences, who also are the ones who in the end have to realize the goals. The choice of using commercial cinema combined with the use of new media through cell phones thus appears as solving the Gordian knot - a universal solution which is able to reach out to everybody. But from an advertising point of view, how unique is the message of Project Everyone?

\section{Project Everyone: A New Take on Advertising?}

Whereas Belz and Peattie in their book Sustainability Marketing focus on commercial marketing, they also deal with social marketing as another 
branch with 'a longstanding tradition of influencing behaviour in the pursuit of societal and environmental goals'. ${ }^{43}$ They note that social marketing shares 'considerable synergy' with sustainability marketing, rather offering a 'social proposition' than a physical product. As examples, they have chosen campaigns in Australia, Denmark, and Canada for cycling or walking, campaigns that try to effect a change in behaviour away from an unsustainable, energy-intensive mode of transportation to a healthier mode, both for the individual and for the planet. ${ }^{44}$

To a certain extent, Project Everyone may seem to share its basic concerns with social marketing, and it is clear that it relies on a number of existing practices in basing its attempt at education, social communication, and raising awareness on solid market research. ${ }^{45}$ As already noted, the new focus proposed by Philip Kotler on people, processes, programmes, and performance also seems to correspond well with this wider vision of marketing, as well as with the general design of the Global Goals Campaign, not least the fact that people stand united, the processes reflect a lot of creativity brought to marketing, there are a number of 'consumer-directed' activities related to the campaign, and as such, it is mostly based on performance. ${ }^{46}$

However, there is one important difference in comparison to social marketing. Whereas cycling campaigns, among other possible examples of social marketing, typically serve the purpose of influencing a target audience to either accept or reject a certain behaviour for social benefit, the Global Goals Campaign and Project Everyone have no such concrete behavioural changes in view. Neither do they aim to promote the United Nations and their decision to adopt the goals as such. Rather, they aim to challenge the worldview of the spectator, to include the audience in a common vision for the future, shared not only by the officials or politicians in the United Nations, but extending to every citizen in every country across the globe. In this, they also aim to challenge the borders of advertising, whereas the four new P's suggested by Kotler basically remain within the world of advertising, focussing on its specific content and form.

If sustainability marketing has followed general marketing strategies in turning from the four P's to the four C's and then to the four new P's, Project Everyone attempts to add a new aspect, a fifth $\mathrm{P}$ for power. As formulated by Richard Curtis,

Kotler, Marketing Management, 25. 
I'm hoping that people will see the ad, remember it, talk about it, share it, and then look into it and actually find that if you are a person who cares passionately about the world in any way, these goals are going to be one of the big machines by which changes happen. So I hope people will watch, laugh, share, act. ${ }^{47}$

The basic aim of Project Everyone is, as we have seen, to '\#telleveryone' about the Global Goals. But telling everyone is not an aim in itself. It is because 'knowledge is power', and the project is based on a conviction that it is necessary to spread the word about the decisions of the politicians in many ways, that neither the politics nor the ordinary news channels will be enough, and so a systematic way of communicating, country by country, is needed. Telling everyone, however, is not innocent - it also contains an agenda of putting pressure on politicians. 'We all need to know what our rights are in order to claim them. This [...] means that we can now begin to hold our politicians to account in addressing the 17 core issues', and according to Richard Curtis, there is also a message from Project Everyone to the world leaders - namely, that they now share a unique opportunity to create enormous results, not only nationally but also globally..$^{48}$

The Global Goals Campaign and Project Everyone strive to bridge the gap between advertising and politics, between cinema and new media, between individual and global goals. There is no target audience - the global audience is the target. There are no specific social benefits to be gained - the survival of the globe is the general gain. There is a call for a global change in behaviour - but these ads contain no specific formulas to obtain the goals. Thus, they may seem quite unique as advertisements, not so much through their strategy as through their general purpose. They rely on their capacity to convince and to reach out to the spectators, encouraging them to explore their own possibilities to share in realizing the Global Goals, and trusting that they will all want to share in realizing a sustainable future for the planet. In emphasizing the uniqueness, both of the global campaign as such and of the Sustainable Development Goals as a very particular moment in world history, they blend global advertising with global politics, letting the films serve as a powerful tool, together with a number of other forms of expressions, all with the aim of actually changing the world. 
However, historicizing the ads offers - just like in the case of Aardman Animations - another possible framework. Yvonne Zimmermann has made an important distinction between on one hand 'advertising film in a narrow sense', 'often called "commercials", "spots" or simply "ads", and on the other 'advertising films in a broad sense, understood as a rhetorical type of moving image that intends to influence opinions, attitudes and behaviour'. ${ }^{49}$ This distinction proves to be quite relevant in this connection, as 'We Have a Plan' is precisely such a rhetorical piece of work. A useful historical point of reference are the documentaries produced at UNESCO, which - with John Grierson as the first director of the Mass Communication division 1947-1948, and with Arthur Elton, Paul Rotha, and Basil Wright continuously engaged with UNESCO until the late 1960 - have heavily relied on the British documentary tradition, as Zoë Druick has analysed in her essay 'Visualising the World'..$^{\circ}$ The framework for this analysis, the history of the General Post Office Film Unit, connects a couple of 'world-themed' films produced for the British Ministry of Information during the war - World of Plenty (1943) and The World Is Rich (1947), both directed by Paul Rotha - as well as a later BBC television series - The World Is Ours (1954) - to World Without End (1953), directed by Rotha together with Basil Wright, indeed an advertising film in the broader sense defined by Zimmermann. The latter, a UNESCO film, which Jack Ellis has called 'the last big brave representation of internationalism from the old Griersonians', ${ }^{1}$ bears many resemblances to the 'We Have a Plan' project. In both films, the opening shows a spinning globe from an outside perspective. World Without End is shot in Mexico and Thailand, linking together people in developing nations across the globe. Both films present the viewer with a number of problems - in World Without End related to health, agriculture, and education - which are 'then solved by UN agencies. [...] The film ends in a crescendo of positive images'. ${ }^{2}$ Whereas

49 Yvonne Zimmermann, 'Advertising and Film: A Topological Approach', in Films That Sell: Moving Pictures and Advertising, ed. Bo Florin, Nico de Klerk, and Patrick Vonderau (London and New York: Palgrave, 2016), 22.

50 Zoë Druick, 'Visualising the World: The British Documentary at UnEsco', in The Projection of Britain: A History of the GPO Film Unit, ed. Scott Anthony and James G. Mansell (London: British Film Institute, 2011), 272-280. See also Richard MacDonald, 'Evasive Enlightenment: World Without End and the Internationalism of Postwar Documentary', Journal of British Cinema and Television 10, no. 3 (2013): 452-474; and Rob Aitken, 'A "World Without End": Post-War Reconstruction and Everyday Internationalism in Documentary Film', The International History Review 35, no. 4 (2013): 657-680.

$5^{1}$ Jack C. Ellis, John Grierson: Life, Contributions, Influence (Carbondale: Southern Illinois University Press, 200o), cited in Druick, 'Visualising the World', 273.

52 Druick, 'Visualising the World', 277. 
'We Have a Plan' starts with images of the UN headquarters, immediately following the initial image of the globe, the emblematic building also appears in World Without End, although later in the film, as the narrator states that '[n]ow, as the world shrinks, the neighbours are closer together. We all live in the same world'. 'We Have a Plan', just like 'We the People', also includes montage sequences representing people from all across the globe, just like World Without End, which features a montage of children from every part of the world. Even though the Sustainable Development Goals in themselves represent a unique moment in history, the advertising strategy adopted rather tends to rely on already established historical patterns, established by UNESCO among others, and blending documentary and advertisement - and both in that sense belonging to the broader category of advertising films as defined by Zimmermann. ${ }^{53}$ Through varying historical circumstances and changing technologies, the UN discourses and communication strategies surrounding common values across the globe thus seem to have remained quite stable.

\section{Marketing Through Sustainability}

The initial comparison in this essay between the ads for Volvo and $\mathrm{H} \& \mathrm{M}$ mostly focussed on issues of sustainability, thus creating an unexpected link to the Global Goals Campaign. This also widens the perspective from these commercials in the narrow sense towards advertising film in the broader sense. However, it would be too simplistic to consider the Global Goals Campaign as a more value-centred enterprise, in contrast to overtly commercial ads.

As we have seen, Volvo had to restore its reputation after being forced to withdraw its controversial slogan, and make less speculative commercials while still drawing on sustainability as a core value. H\&M on the other hand, as we have also seen, had to defend itself against repeated accusations on the use of child labour, and turned to social responsibility and sustainability through recycling as means of restoring its tarnished brand. Similarly, the Global Goals Campaign may be seen not only as a way to market the goals as such, but just as much as a means to rebrand and revive the image of the often-contested United Nations through the goals: in other words, a way to show its efficiency, its universal relevance, and its engagement and care

53 See also Yvonne Zimmermanns's chapter 'Advertising and Avant-Gardes' and her discussion on Grierson. 
for global development to the world. ${ }^{4}$ However, one might question the real impact of the campaign.

Even though the Global Goals Campaign by Project Everyone as a whole must be considered successful - 'we reached 3 billion people in 7 days' 55 - we do not really know about the impact of 'We Have a Plan'. It was 'premiered across 34 countries', ${ }^{6}$ but how many people actually saw it? If we look at the number of views on YouTube, it cannot be considered very successful as a commercial campaign, with 6000 views on SAWA and 21,000 views on the Aardman Animation home page for 'We Have a Plan' (and slightly more than 6000 views for the follow-up ad with the same title on YouTube, launched by the UNDP).

The contrast to an earlier UN ad, ' 805 Million Names', made for the World Food Programme and addressing the second Sustainable Development Goal, 'No Hunger', is striking. This ad, featuring Zlatan Ibrahimović, was made by Forsman \& Bodenfors, thus linking it both to the Volvo and to the H\&M ads discussed above. As Paris Saint-Germain played against Caen on 14 February 2015, Ibrahimović, after scoring a goal, pulled off his sweater to reveal 50 new names added to his existing tattoos. These 50 names had been chosen to represent the 805 million people suffering from hunger across the globe. The gesture, which earned the player a yellow card, was shown in an ad with Ibrahimović himself talking about his motives, as well as in a longer version documenting the process of making the ad. According to Forsman \& Bodenfors, the ad has reached over 1.2 billion people, with 16.8 million combined views, and has resulted in 4.4 million social interactions as well as approximately 4600 news articles. ${ }^{57}$ The huge success, however, was due less to the United Nations, or even to Forsman \& Bodenfors, than to Zlatan Ibrahimović himself, who contacted the company and wanted them to make this ad. Researcher in business administration Eva Ossiansson has commented on his systematic way of working on his brand, in which both the Volvo ad portraying him as a global Swede (discussed in the chapter on Volvo), and the UN campaign, broadening his brand as a global role model,

54 On Wikipedia, a post entitled 'Criticism of the United Nations' runs to nearly 4000 words, and spans from philosophical, moral, or administrative criticisms to criticisms of scandals. Thus, interpreting the Global Goals Campaign partly as a means to respond to the critics turns out not to be too far-fetched.

55 Project Everyone, home page, https://www.project-everyone.org (last accessed 6 April 2021).

56 Ibid.

57 Forsman \& Bodenfors, '805 Million names', http://www.fb.se/work/world-foodprogramme/805-million-names (last accessed 6 April 2021). 
contribute to creating and developing his own myth..$^{8}$ When commenting on the Volvo ad, he emphasized that he makes his own choices about whom to work with:

Volvo was small before meeting me! First it was 'Made by Sweden', now it is: 'Made by Zlatan'. My God, during the first week after the ad Volvo sold more than they normally do in six months. This is really nothing to brag about, the result speaks for itself. But that is the kind of thing I'm looking for, exciting projects. To work with small companies and make them [...] gigantic. 59

The '805 Million Names', just like the Global Goals Campaign and Project Everyone, aim to spread the word rather than just launch a commercial. Still, they also promote certain brands - that of the United Nations, of Aardman Animations, or of Zlatan Ibrahimović. The varying degree of success reveals a fundamental aspect of the logic of advertising, apart from the benefit of using a skilful advertising company. That is, that however much 'high' values -such as sustainability - are used for promotion, whether it is for commercial or rhetorical purposes primarily, they mean little or nothing in comparison to a 'real' brand, acquired outside of the world of advertising, such as that of Zlatan Ibrahimović. Here, the aims of promoting the brand of Ibrahimović himself and the brand of Volvo, or the brand of the United Nations in eliminating hunger globally, actually converge. A brand, then, is not only an outcome of advertising but also a tool or a means to promote the very product of advertising; thus, the ad in the more narrow sense merges with the broader vision of advertising, aiming to change values: 'opinions, attitudes, and behaviour'. ${ }^{60}$

As the Global Goals Campaign was launched, this was probably the most ambitious effort in the history of advertising film ever to reach out globally in advertising pure values. The idea, to succeed where the first attempts to advertise the millennial goals had failed, was met with high ambitions, not only using all available new media platforms, but also, last but not least, connecting to historical traditions, such as the UNESCO films or the use of

$5^{8}$ Eva Ossiansson quoted in Andreas Rågsjö Thorell, 'Han vet att han formar sin myt efter sitt agerande', Resumé, 17 February 2015, https://www.resume.se/nyheter/artiklar/2015/02/17/ han-vet-att-han-formar-sin-myt-efter-sitt-agerande/ (last accessed 6 April 2021).

59 'Zlatan - legenden', Camilla Tollstoy, Scandinavian Traveler, 31 May 2016, https://scandinaviantraveler.com/se/manniskor/zlatan-legenden (last accessed 6 April 2021).

60 Thanks to Yvonne Zimmermann for useful thoughts in this connection. Zimmermann, 'Advertising and Film', 22. 
Aardman animations, and using cinema as a major platform. Today, the knowledge about the Sustainable Development Goals is widespread across the globe. The question remains, however, to what extent this result can be ascribed to the Global Goals Campaign and Project Everyone.

\section{Bibliography}

Aitken, Rob. 'A “World Without End”: Post-War Reconstruction and Everyday Internationalism in Documentary Film.' The International History Review 35, no. 4 (2013): 657-68o.

Belz, Frank-Martin, and Ken Peattie. Sustainability Marketing: A Global Perspective, 2nd ed. West Sussex: Wiley, 2012.

Cook, Malcolm. 'All You Do Is Call Me, I'll Be Anything You Need": Aardman Animations, Music Videos and Commercials.' In Beyond Stop-Motion Film: Production, Style and Representation in Aardman Animations, edited by Annabelle Honess Roe. London: Bloomsbury, 2020.

Dickason, Renée. British Television Advertising: Cultural Identity and Communication. Luton: University of Luton Press, 2000.

Druick, Zoë. 'Visualising the World: The British Documentary at UnEsco.' In The Projection of Britain: A History of the GPO Film Unit, edited by Scott Anthony and James G. Mansell, 272-28o. London: British Film Institute, 2011.

Ellis, Jack C. John Grierson: Life, Contributions, Influence. Carbondale and Edwardsville: Southern Illinois University Press, 2000.

Florin, Bo, and Astrid Söderbergh Widding. 'Dag Hammarskjöld i FN:s filmarkiv.' Signum 1 (2006): 12-17.

Florin, Bo, Nico de Klerk, and Patrick Vonderau, eds. Films That Sell: Moving Pictures and Advertising. London and New York: Palgrave, 2016.

Kotler, Philip. Marketing Management, 14th ed. Harlow: Pearson, 2012 [1967].

MacDonald, Richard. 'Evasive Enlightenment: World Without End and the Internationalism of Postwar Documentary.' Journal of British Cinema and Television 10, no. 3 (2013): 452-474.

McCarthy, E.J. Basic Marketing: A Managerial Approach. Homewood: Irwin, 1960. 
